\title{
Pandemic flus and vaccination policies in Sweden
}

\author{
Britta Lundgren and Martin Holmberg
}

\section{Introduction}

During the summer of 2010, unexpected reports of narcolepsy in Swedish children and adolescents after vaccination with the pandemic influenza vaccine Pandemrix came to the attention of the Medical Products Agency (MPA). The main features of this condition are excessive daytime sleepiness, sudden loss of voluntary muscle tone (cataplexy) that may be triggered by strong emotions, vivid dreamlike images/ hallucinations (hypnagogic hallucinations), and paralysis during sleep onset or when waking (sleep paralysis). Vaccination of the entire population had been recommended by the National Board of Health and Welfare as a preventive measure to stop the spread and mitigate the feared consequences of the $\mathrm{A}(\mathrm{H} 1 \mathrm{~N} 1)$ pandemic that began in the summer of 2009. Over 60 per cent of people living in Sweden were vaccinated during the fall of 2009 with a new vaccine. This was the single largest public health intervention in response to an outbreak in Swedish history.

Five different vaccines were developed during the pandemic and were approved by the European Medicines Agency (EMA) and the EU commission in a special fast-track procedure. ${ }^{1}$ Sweden had signed a contract with one of the producers of the vaccine Pandemrix (GlaxoSmithKline). This vaccine contained a new formulation for the adjuvant, the component of a vaccine that enhances the immune response to the included antigen. Since the pandemic vaccines were approved under exceptional circumstances, information on possible side effects 
was limited. However, from the studies performed, the results showed that Pandemrix had very good efficiency, giving rise to protective antibodies to a higher degree than ordinary unadjuvanted influenza vaccines.

According to the MPA, between 200 and 300 cases of narcolepsy are estimated to have resulted from the Swedish mass vaccination programme; the exact number is uncertain, since the criteria for vaccineassociated narcolepsy are variable. Several independent research reports have been published in other countries, confirming the association of narcolepsy with Pandemrix. ${ }^{2}$ This serious medical side effect was totally unexpected and has played a significant role in shaping public, medical, and authorities' opinions regarding flu epidemics and flu vaccines. Public trust in medical, social, and political authorities decreased. This is particularly evident in public debates in the traditional media as well as on blogs, websites, and Facebook groups. Although it is difficult to measure the exact uptake of seasonal flu vaccination in many regions, coverage has decreased since $2009 .{ }^{3}$ Thus far, it has not affected the uptake of vaccines in the general child vaccination programme, as opposed to the case of the MMR vaccine following the 'Wakefield affair. ${ }^{4}$

The mass vaccination programme and the resulting side effects point to the need for a historical and national perspective on the development of flu vaccination practices. This chapter discusses pandemic influenza as both an old and a contemporary problem, and places it within the framework of national and international flu vaccination practices. The chapter is based on earlier research on flu pandemics, on public documents, and on interviews carried out in March 2013 with parents of children with narcolepsy and officials working with pandemic planning at the Swedish national level.

\section{Vaccinations and epidemics in Sweden}

The history of immunisation programmes in Sweden began in the second half of the eighteenth century with the introduction of smallpox inoculations. During that entire century, smallpox was a serious and prevalent childhood disease in Sweden, as in other European countries. When inoculations began on a large scale in the 1860 s, only physicians were licensed to perform them, and they were often resisted 
by a reluctant and sceptical public. Nevertheless, the incidence of smallpox decreased slowly during this period. How much the inoculations contributed to this decrease has been questioned, but the efforts were generally considered successful by the authorities. In contrast, the public sometimes blamed the recurring epidemics on the inoculations. ${ }^{5}$

When Jenner's new method of vaccination was published in 1798, it was quickly adopted in Sweden, beginning in 1801-2. ${ }^{6}$ By this time, the public was more accepting, recognising the effectiveness of the vaccinations. Initially, anyone was free to administer them, but this changed after vocal criticism of unskilled vaccinators. After 1810, district physicians had to approve all vaccinators.

The limited number of approved vaccinators was a problem for mass implementation, and the low vaccine coverage of the population was a concern. A law on vaccination was adopted by Parliament in 1816, one of the most severe in Europe, making smallpox vaccination compulsory for children under the age of 2 . The clergy and their assistants were appointed as vaccinators, breaking the monopoly of the medical profession and providing efficient vaccination organisation.

The vaccination was very successful and incidents of the disease decreased dramatically during the nineteenth century, although there were still small regular outbreaks. But by the end of the century, there were hardly any smallpox deaths. There were a few isolated occurrences during the twentieth century, with the last one in 1963, affecting twenty-seven persons in the Stockholm area. This led to the voluntary mass vaccination of more than 300,000 people. ${ }^{8}$ This mass vaccination resulted in a few serious adverse effects and special clinics for patients with vaccination complications were set up. ${ }^{9}$ General smallpox vaccination continued on a compulsory basis, with liberal exemptions, until 1976.

Many epidemic diseases were drastically reduced during the first decades of the twentieth century. Smallpox, typhoid fever, and cholera had almost vanished by 1900 as a result of vaccination and sanitary reforms, although diphtheria, pertussis, and measles were still (diminishing) realities. Tuberculosis was still prevalent and polio became a growing threat during the first half of the twentieth century. ${ }^{10}$ The three infectious diseases most feared during this period were tuberculosis, polio, and influenza, and they became increasingly urban phenomena 
as Sweden urbanised during the early twentieth century. Polio has been eliminated since the 1970s and tuberculosis is now a rare disease in Sweden, though influenza is as prevalent as it was a hundred years ago, a fact that is seldom acknowledged. Each year, up to 10 per cent of the population can be infected, and influenza-related complications cause hundreds of thousands of hospitalisations across Europe.

Following smallpox vaccination, tuberculosis and diphtheria vaccines were introduced during the 1940s, and included in the first general child vaccination programme of 1947 , shortly followed by tetanus and pertussis vaccines. Midwives and paediatric nurses in the web of maternity and child clinics were appointed as the main vaccinators. The goal from the start of the programme was to inform pregnant women and vaccinate as many children as possible. In 1957, polio vaccination was added to the programme, with a Swedish-produced deactivated polio vaccine. Using this vaccine, polio was successfully eliminated in Sweden within a decade.

In 1970, the first measles vaccine was introduced, followed by the MMR triple vaccine in the early 1980s. Tuberculosis vaccination was taken off the general vaccination programme in 1975, and in 1979 the old pertussis vaccination was discontinued due to poor effectiveness and too many adverse effects. A new acellular pertussis vaccine was reintroduced in 1996, after the incidence of pertussis had begun to rise again during the 1980s.

In summary, Sweden rapidly introduced a general vaccination programme after the Second World War and had managed to adapt to changing situations, maintaining a high level of public trust in official vaccination policy.

\section{What kind of a problem is influenza?}

The influenza A virus varies in terms of surface structure, giving rise to a large number of subtypes. The origins of all subtypes are aquatic birds, but several mammals, including humans, can be infected by some subtypes. The subtypes affecting humans often change in minor ways from year to year, but once in a while major new variants emerge that can cause pandemics.

In the industrialised countries that have undergone epidemiological transition, ${ }^{12}$ where infectious diseases have been replaced by chronic 
diseases as the main causes of death, influenza still causes substantial mortality and morbidity, and returns every year. In fact, this mortality and morbidity is largely the effect of the combination of influenza with prevalent chronic conditions such as cardiovascular, respiratory, and metabolic diseases. It can be argued from this that influenza is not one single epidemic disease but a syndemic ${ }^{13}$ of a viral disease together with several chronic conditions that are increasing in modern societies. Despite this, the authorities' response to seasonal influenza outbreaks has often been indecisive and ambiguous, with influenza-associated mortality often seen as inevitable.

Since the Second World War, vaccination has been considered the magic bullet to protect people from influenza, whether seasonal or pandemic. However, there remain significant problems associated with the current influenza vaccines that have not yet been solved, such as short-lived protection, narrow strain specificity, low effectiveness in protection against morbidity and probably also mortality, and potential neurological side effects such as Guillain-Barré syndrome and now also narcolepsy for some vaccines. There is no straightforward public health solution for dealing with seasonal or pandemic influenza. Neustadt and Fineberg, ${ }^{14}$ in their review of the circumstances surrounding the decision to mass vaccinate the US population in 1976 as a result of the so-called Fort Dix incident, called it a 'slippery' disease. The five features they identified that combine to make influenza slippery are: the changing character of the influenza virus; the lack of effectiveness of influenza vaccines; that influenza symptoms are widely misunderstood; that influenza is not the only virus to give rise to influenza-like illness; and, finally, that the multitude of causes of flu-like illness makes it difficult to estimate the year-to-year impact of influenza on public health.

In order to match vaccines with currently circulating influenza strains, a WHO network of collaborating centres for influenza surveillance was created in 1948. A recommendation for the antigenic composition of the following year's influenza vaccine is made by the WHO and passed on to vaccine manufacturers. As of 1999, there have been two recommendations per year, one for the northern hemisphere and one for the southern hemisphere. ${ }^{15}$ The WHO issues regularly updated influenza vaccine position papers, the most recent in 2012. Annual influenza vaccination has thus become a global concern for the WHO. However, many countries still have difficulties reaching the collectively 
decided goals for vaccine coverage. In many developing countries, influenza is not seen as a dominant public health problem; many other infectious diseases compete for attention and resources. Consequently, there is no global consensus on the public health importance of seasonal influenza and national vaccination programmes are not a top priority in many low- and middle-income countries.

The pandemics that appear irregularly a few times each century spread with increasing speed. Several studies have shown that global air travel is now a major driving factor in dissemination. ${ }^{16}$ The annual influenza epidemics also have an international pattern of spread, where the same strains visit the southern and northern hemispheres during their cooler periods, while tropical and subtropical countries have a less seasonal pattern of appearance. ${ }^{17}$

Influenza pandemics have had an impact on public health, economy, and societal functions to different degrees throughout history, and since the Spanish flu of 1918 have been defined as a health threat by the medical profession. Since the beginning of the twenty-first century, they have also been declared a matter of national and international security, for health, societies, and states. This has fundamentally changed the way in which pandemics are perceived, with governments now anticipating severe pandemics of a magnitude similar to the Spanish flu. Most high- and middle-income countries have pandemic preparedness high on their agendas, strengthening emergency infrastructure and stockpiling antiviral pharmaceuticals and vaccines.

These global concerns have been formalised in the World Health Report $2007^{18}$ and the new International Health Regulations adopted 2007, with increased obligations for member states to have adequate surveillance, reporting, and preparedness capacity for international health threats, including new influenza pandemics.

\section{Historical perspectives on influenza}

The history of influenza is long, but knowledge about the viral cause, the variability of the virus and the disease, the factors necessary for transmission, and the methods to stop its spread is more recent and still incomplete. The American historian George Dehner provides a historical perspective on the pandemic of 2009 and the recurring concerns with influenza pandemics. ${ }^{19}$ Some descriptions of epidemics of 
respiratory disease from antiquity and medieval times could well have been influenza, and from the sixteenth century onward, influenza-like epidemics have been reasonably well described.

There have been an estimated thirty-one influenza pandemics since the first well described pandemic of 1580 . From the end of the nineteenth century, five have impacted Sweden: Russian flu 1889-90, Spanish flu 1918-20, Asian flu 1957-58, Hong Kong flu 1968-70, and most recently $\mathrm{A}(\mathrm{H} 1 \mathrm{~N} 1)$ or swine flu 2009-10. How pandemics compare with each other in terms of severity is still a matter of debate; epidemiological data are incomplete and there is no agreed measure of severity. Variations in mortality and morbidity are nonetheless obvious, and it is often claimed by experts that no two pandemics are alike.

Of the above mentioned influenza pandemics, the Spanish flu pandemic of 1918-19 was particularly virulent, killing an estimated 40-50 fifty million people worldwide. ${ }^{20}$ In Sweden, the death toll was around 35,000 people, 99 per cent of whom were below the age of 65 . The total Swedish population was then around 5.8 million, and the rapid population increase seen in the previous years was halted during the two to three years following the pandemic. The effects on society were profound, having both political and military ramifications, and adversely affecting public trust in the authorities' ability to handle such catastrophes.

Reports on Spanish flu focused on how it impacted the military. Sweden was neutral during the First World War, but its military forces were reorganised and training increased as a consequence of it. Barracks were filled with conscripts and new cohorts were being called in each fall. Respiratory tract infections were common in crowded quarters, and when the flu struck the country in the fall of 1918, mortality rose dramatically among these new conscripts. ${ }^{21}$

Several local reports conveyed a state of despair and disorder, but also solidarity and local ways of coping with the hardships. Health care was affected by absenteeism, overcrowded wards, and the lack of specific treatment for serious cases. Inexperienced doctors were often sent out to the countryside to help, and some attested to their helplessness when confronted with dying patients. ${ }^{22}$ The incidence of morbidity and mortality varied in the country; some cities and smaller communities were severely affected, with over 70 per cent of the local population falling ill and many young people dying. ${ }^{23}$ 
It would take thirty-nine years for the next pandemic to hit Sweden in 1957. During the intervening period, liberals and then social democrats were firmly in power, universal suffrage was instituted, and the welfare state was largely in place. What was to become known as the 'Swedish model' of agreement between conflicting interest groups in the labour market was signed in 1938.

The fact that influenza is a viral disease was shown conclusively in 1933. When the virus was successfully grown in embryonated eggs, the first vaccines could be manufactured. This was important for the allied war effort during the Second World War, and influenza vaccines were tested on soldiers in the 1940s. ${ }^{24}$ Influenza vaccine production in Sweden began at the National Bacteriological Institute (SBL) in 194546 , at a time when memory of the Spanish flu was still alive. ${ }^{25}$ Trust in the general vaccine programme was at this time high and one of the interviewed officials (born in the early 1950s) remembered his parents' attitudes:

I remember the older generation, they thought vaccinations were very important and it was almost kind of solemn to go and get vaccinated, it was not just a mundane question of routine. ${ }^{26}$

There were many reasons for this positive attitude towards vaccination, which had to do with the progress of modern medicine in general, and specifically with the 'revolution of the healthy body', with its roots in the 1930s, as shown in national mass movements of gymnastics, fitness, vegetarianism, and even nudism. ${ }^{27}$ The state was considered a natural actor in promoting the well-being of its citizens, and the ties between individuals and state were mutually very strong. ${ }^{28}$ The new institutions for social support and general welfare brought social security but also a growing individual dependence on the state and its authorities.

Asian flu was the first pandemic to occur in this era of strong ties between the state and the individual, and also in the era of virology. The pandemic was considered by the WHO as relatively mild and not a major threat to society, though the response to it was enacted as a war against the virus. ${ }^{29}$ The attitude of the time was one of scientific optimism, and trust in vaccines and antibiotics was high. When Asian flu finally hit Sweden in October 1957, it came suddenly and with force. A large number of soldiers in some regiments fell ill, and many schools 
had to close. Significant absenteeism was reported in the postal service, telegraphic service, and the national railway company. The Medical Board issued general advice to the public, but responsibility was placed mainly on local authorities. Special epidemic wards opened in some larger cities.

The WHO had distributed the new virus strain to laboratories and vaccine producers around the world before the pandemic emerged, allowing time for some vaccine production. Sweden had received the A-Singapore-1/57 strain in June 1957, but it grew poorly and a new adapted strain had to be obtained from Statens Serum Institut in Denmark. Sufficient vaccine was ready for trials in October 1957, just when the pandemic struck Sweden. The efficacy and safety of the vaccine was tested on 3,000 military recruits, and between 69 and 86 per cent protection was achieved with two doses. ${ }^{30}$

Initially, health-care workers, in the hospitals specialised in epidemic diseases, home care personnel, and later emergency ward and ambulance drivers were given the vaccine. Some travellers were also vaccinated as well as a few in medical risk groups, mainly those with serious cardiovascular or respiratory disease. ${ }^{31}$

Media coverage was extensive and comparisons with the Spanish flu were common. Returning travellers infected abroad were often singled out in media reports. Scientific interest in the phenomenon of influenza pandemics seemed low, however, and very few scientific reports were written in medical journals about the pandemic. The experts that appeared publicly were often assigned by the National Bacteriological Laboratory or the National Medical Board. ${ }^{32}$ A report in the medical literature was published afterwards, where the costs to society of Asian flu were calculated at approximately 130 million kronor (about 1,5 billion kronor today, or about $€ 154$ million), ${ }^{33}$ and it was estimated that half of that cost would have been saved if there had been sufficient quantities of the vaccine for the whole population. The pandemic peaked in November and around 15 per cent of the population was estimated to have been affected before the season ended in April the following year. The lethality was, nevertheless, relatively low. ${ }^{34}$

Eleven years later, during the 1968 Hong Kong flu pandemic, the situation had changed somewhat. There was still an atmosphere of economic and scientific optimism, but trust in the omnipotence of medical 
science was decreasing. ${ }^{35}$ Emphasis was placed more on influenza pandemics as natural disasters and mitigation of the consequences became a priority. However, the general tone in the media was neutral, calm, and undramatic.

The first international reports of the Hong Kong pandemic came in July 1968, when it had already been raging in Asia for some time. It began its spread among larger parts of the North American population in September 1968, and appeared at about the same time in some parts of Europe. In Sweden, there were initially sporadic cases during the fall of 1968, though the epidemic gained speed in the first months of 1969. A second, more serious wave hit the country during the next winter season, 1969/70.

The vaccine situation during the Hong Kong pandemic was similar to the one eleven years earlier. Production of the influenza vaccine at SBL was not nearly sufficient to meet the need and large quantities had to be imported from the USA. ${ }^{36}$ The medical risk groups for serious disease were extended, including diabetics and patients with other metabolic diseases, in addition to the earlier groups of patients with cardiovascular or chronic lung diseases. As before, selected professional groups, mainly health-care workers, were vaccinated. The newly formed Board of Health and Welfare warned about the vaccine shortage but did not want to issue a priority list for vaccination. Instead, this was left to the county epidemic boards. During the second wave in late 1969, more of the vaccine was available and the national authorities issued recommendations regarding who should receive it.

After the Hong Kong flu pandemic, the national production of influenza vaccines was subsequently maintained at a relatively low level, sometimes complemented by purchases from abroad when production failed. Problems caused by shortages of staff or money, or sometimes a shortage of embryonated eggs, were not uncommon. Production was discontinued in the fall of 1982 due to run-down production facilities. ${ }^{37}$ In 1993, the remaining vaccine production (mainly polio, diphtheria-tetanus, and measles vaccines) was separated from the diagnostic laboratories and continued as a state-owned company for about five years before it was sold off to private owners. Thus, owing to a series of political and economic decisions, there was a slow erosion of state-owned vaccine production over a period of just over a decade. $^{38}$ 


\section{Nordic vaccine production}

When discussions about the need for increased pandemic preparedness intensified around the turn of the century, the question of national or regional influenza vaccine production began to appear on the agenda. It was feared that the few large companies supplying influenza vaccines would not be able to meet the needs of the market in a pandemic situation, and that smaller countries, in particular, would not be supplied. The question of joint Nordic vaccine production was brought forward, mainly by Danish authorities, with discussions starting in 2000.

In June 2005, the Nordic council of ministers decided to investigate the possibility of joint production of influenza vaccine for the Nordic region. A working group reported in November on two possible models, one with publicly controlled production and one with a publicprivate partnership (PPP). This was followed up by an investigation by Statens Serum Institut in Denmark of the possibilities of a public solution, and a Swedish government special commissioner explored the PPP alternative. The Swedish commissioner's conclusions were that production should be based on close collaboration with an established vaccine producer, that the emerging cell-based technology for the influenza vaccine production should be awaited, and that further negotiations with some major private producers in the meantime should be continued. ${ }^{39}$

This investigation resulted in the Swedish government deciding to commit themselves to a Swedish solution in cooperation with existing international pharmaceutical companies before a common Nordic agreement could be reached. The motivations for this decision have not been made public, but both strategic thinking about future influenza vaccine developments and neo-liberal ideology might have played a role. One official at the National Board of Health and Welfare reflected on whether it would have been advantageous for the Nordic countries to have their own state-controlled vaccine institutes.

We have made everything commercial now, but I do think there would have been some advantages to have it state controlled. But still, on the other hand you never know ... the vaccine experts will not be isolated in an ivory tower, they will have contacts with the vaccine industry, so the only thing you can do in this globalized world is to describe as well as you can exactly what the connections look like. ${ }^{40}$ 
Several groups, both from the industry and medical experts, lobbied for a new production facility to be built in Sweden, whether private, state owned, or state subsidised. Since the investment costs would be high and the market uncertain, and considering the fact that EU rules on competition could be violated by state involvement, there was no government interest in such a solution.

\section{Seasonal influenza vaccine policies}

Seasonal influenza vaccines have been in use in Sweden since the 1970s, but at a low level and mainly to protect patients with chronic conditions such as cardiovascular and chronic lung diseases, as well as health-care workers. A cost-utility analysis performed in 1987 established that the costs for general vaccination did not offset the gains in direct health-care costs. A study comparing influenza vaccination in eighteen developed countries between 1980 and 1992 showed a ten-fold difference in the number of vaccine doses used among the countries studied. ${ }^{41}$ Sweden, together with Denmark, Finland, and a few others, was at the lower end. Most countries had, by 1992, recommendations for vaccinating those aged over 65, but in the Nordic countries only Norway and Iceland had adopted this policy.

Why were the Swedish authorities reluctant to adopt the expanded use of seasonal influenza vaccination? One probable reason is the influence of studies published by Hoskins in the early 1970s, which made an impression on the Swedish Board of Health and Welfare, the authority issuing vaccination recommendations. The results of these studies, also called 'the Hoskins' paradox', seemed to show that repeated annual vaccinations would not confer protection against epidemic influenza in the long term. However, revisiting Hoskins' data reveals that this conclusion cannot be substantiated. ${ }^{42}$ This has also been corroborated in later studies, and the conservatism in recommending annual influenza vaccination lost its strength during the 1990s. New studies on the benefits of vaccinating older persons in institutions also made a case for increasing annual vaccination. In 1997, new recommendations were finally issued on annual influenza vaccination for medical risk groups and those aged 65 and over, harmonising Swedish policy with neighbouring countries. 
Around fifty mainly industrialised countries and some countries in rapid economic development vaccinated defined high-risk groups, including the elderly, in the early years of the twenty-first century. No country fully implemented its vaccine recommendations, however, and the World Health Assembly therefore set the goal of vaccination coverage for elderly people of at least 50 per cent by 2006 , and 75 per cent by 2010 . These goals were not reached in many European countries. In Sweden, coverage was around 65 per cent of those aged over 65 before the 2009 pandemic, but has since dwindled to $50-55$ per cent for the same age group.

Some Swedish officials still doubt the cost-effectiveness of seasonal influenza vaccination and stress the importance of putting pressure on the industry to improve the vaccines:

We have a problem that seasonal influenza vaccines are not really effective. The pandemic vaccine was quite good if you consider its effectiveness, but those that we have each autumn .... it is shown that they are not so good ... Our role here is to put pressure on the vaccine industry and tell them that now you have to come up with something that works. We are not going to give you free promotion year after year, and this is a huge source of income for the industry. ${ }^{43}$

Another official was similarly critical of seasonal vaccination:

I am a little critical of those seasonal vaccinations. You shouldn't mess around too much with the immune system if you don't have to, with bad vaccines ... It is a quite bad vaccine, 60 percent protection at best. In what other cases would we tolerate that $?^{44}$

\section{Pandemic preparedness planning}

Planning for a coming influenza pandemic had been ongoing for many years before 2009. Especially after the SARS outbreak in 2002 and the spread of A(H5N1) avian flu from 2003, the lack of a national contingency plan for a pandemic had become an issue. At the same time, the discourse on 'biosecurity' had also begun to dominate over traditional public health discourses with regard to dealing with infectious disease outbreaks. Aside from public health officials thinking in terms of epidemiology, microbiology, and risk assessments based on historical experience, a new discourse emerged related to scenario-based 
exercises, crisis management, and pandemic preparedness in Sweden as well as in many other western countries. ${ }^{45}$

In the Swedish pandemic contingency plan finalised in 2005, two strands of reasoning were elucidated: one comprising methods to protect the population using surveillance, preventive measures, and strengthened capabilities of the health-care system, the other focusing on protecting critical structures, essential services, and business continuity (or in the terms introduced by Lakoff, ${ }^{46}$ population security versus vital systems security). The challenge was how to balance and integrate these two approaches to dealing with a pandemic. As became clear during the course of the 2009 pandemic, this was not always harmonious.

Before 2009, several large and small exercises were undertaken to examine the different aspects of dealing with a pandemic, mostly based on scenarios with a serious impact. A large EU-wide exercise 'Common Ground' focused on communication between member states and with the European Commission. National exercises dealt with crisis management and the logistics of distributing antivirals and vaccines. Obviously, mass vaccination could not be carried out; instead, computer simulations of different vaccination regimes were used. Sweden signed an advance purchase agreement with a major vaccine supplier and logistics plans were put in place for distributing the vaccine. When the WHO declared phase six of the pandemic, the trigger would be pulled to enact the agreement.

Other interventions aside from vaccination were also discussed. No strong evidence for the effectiveness of school closures was found. Other, more drastic measures, such as travel restrictions or temporary bans on social events and gatherings, were considered too costly and impractical. Much emphasis was placed on personal hygiene measures, notably hand washing. Centrally produced posters were distributed urging people to wash hands often with soap and water, to cough and sneeze into the bend of the arm, and to stay home in the case of feeling sick.

Even at children's day care institutions, to wash their hands and sing Twinkle twinkle little star, and stop washing after singing the first verse. ${ }^{47}$

Nowhere in the authorities' recommendations was the use of hand sanitisers mentioned, but it appeared several times in the media as an 
efficient way to protect yourself and others. There was a scramble for these sanitisers and stocks were quickly emptied. The toilets of official buildings, schools, hotels, and stores were equipped with them. They were carried in pockets and handbags and publicly used in a ritualistic way. The Minister of Health proudly opened her handbag in front of TV cameras to show her sanitiser bottle, indicating that this served as a visible sign of being a responsible citizen.

For the first time in history, it was also possible to build large stockpiles of antiviral drugs for dealing with a pandemic. Although there was scepticism among some experts about the utility of such stockpiles, politicians were eager to show their determination. These drugs had earlier been sparingly used in medical treatment and prophylaxis. Now they were going to be used to protect not only those who were ill or at risk of serious disease, but also those in functions essential to society. Several examples were given, such as those working in garbage collection, elevator repair and maintenance, public transportation, and loading bank cash machines. The plan was to produce a catalogue of workplaces and employees that should be protected. However, swine flu hit Sweden before there was time to produce such a catalogue, or to reach an agreement on how to interpret the criteria for what should be considered essential functions. Aside from deciding the targets for prophylaxis, there was also the question of who should be responsible for implementing it: public health officers or crisis management administrators. The stockpiles stayed almost unused during the whole pandemic and are now require renewal or downsizing.

\section{Preparedness put to the test}

The 2009 swine flu pandemic differed from what was expected and planned for. It carried an unexpected virus (H1N1 instead of the H5N1), had an unexpected place of origin (Mexico and California instead of South East Asia), and this time it was young and healthy people who were pronounced as at risk, in addition to pregnant women, the obese, and the chronically ill.

Despite these unexpected elements, Sweden was in most respects technically well prepared to meet the pandemic. The concerned central authorities and all the county councils had some sort of pandemic planning in place. Many national level actors were involved, such as 
the government and government offices, the National Board of Health and Welfare, the Institute for Communicable Disease Control, the Medical Products Agency, the Swedish Civil Contingencies Agency, and the Work Environment Authority. Together they formed a National Pandemic Group that met frequently before and during the pandemic to share information. Actors at the regional and local level were the county administrative boards (which act as the regional arm of central government), county councils (which are responsible for health care), county medical officers (responsible for public health), and the municipalities (with their responsibility for social services, schools, public transport, etc.).

We had been thinking about this for years, and this was interesting because the pandemic was one of the few things happening in the world where we actually were well prepared. For ten years we had worked out pandemic plans in Sweden and the EU. And we had a very obvious rehearsal with bird flu some years earlier. So we brought our plans and started the meetings. We did what we had said we would do. ${ }^{48}$

The logistics of vaccine distribution had been well designed. Shipments came to one place in southern Sweden each week, and from there were transported around the whole country within a few days. In most vaccination stations, good records were kept so that any unused vaccine lots could be redistributed. The greatest problem was that the producer was not always able to meet the promised quota, giving rise to local shortages. This created a lot of frustration among people who had queued for hours to get their shot. But all in all, this was a display of efficiency in the tradition of Swedish vaccination practices.

There were, nevertheless, difficulties when it came to the actual decisions about who should be prioritised for the vaccine. The fact that the medical risk groups in some ways differed from earlier pandemics was one. New groups shown to be at risk for serious disease were pregnant women and the pathologically obese. Children, though they seemed not to become seriously ill as often as adults, were at greater risk of being infected, and were thus important spreaders of disease. As in other influenza pandemics, there was a shift of mortality compared with seasonal influenza, from the very old to young and middle-aged adults, but they were the least willing to be vaccinated. 
Here we had another panorama. Here we saw young adults in their upper teens, healthy people ... who fell very ill, we saw them in ECMO [extracorporeal membrane oxygenation, where a machine takes over the work of the lungs and sometimes the heart], and then the risk groups sort of fail: who are the risk groups? ... All in all you had to vaccinate the young ones, because they are the ones who spread the disease. So I think you will have to reason in a correct manner. Then it happened to be such bad luck that precisely this group of young people suffered from this terrible side-effect [narcolepsy], but fundamentally it was correct scientific reasoning. It was logical. ${ }^{49}$

Because of the urgency, the pandemic vaccine had not been extensively tested in children. Furthermore, there was the question of whether there would be enough vaccine produced in time, and if not, should any particular risk groups be prioritised? The public health experts were not all in agreement, but the politicians decided quite early on that the only politically possible solution was to buy enough of the vaccine to immunise all Swedes with two doses. Nevertheless, some risk groups were prioritised, together with health-care workers, to receive the vaccine first. As the official Swedish evaluation has shown, there is a need to discuss concepts such as 'risk groups', 'target groups', and 'vulnerable groups' in much greater depth if the concepts are to be usable in the management of future pandemics. ${ }^{50}$

\section{How was mass vaccination perceived?}

When deciding quickly about measures to counter a new pandemic, authorities are often in a situation of placing a bet without knowing the odds. There is substantial risk, according to Neustadt and Fineberg, of over-simplifying the problem and of 'group think' in a network of likeminded experts. The question during the 1976 Fort Dix incident was: if this is a gamble, is it not better to gamble with money rather than people's lives? In a similar vein, the Swedish government opted for a quick mass vaccination campaign in response to the 2009 swine flu pandemic. When it was all over, it could be argued (and was by some) that it had been unnecessary and a waste of taxpayers' money.

The seriousness implied by the WHO decision to declare swine flu a pandemic without explicit judgements about its seriousness made mass vaccination a rational choice for wealthy countries with the critical 
infrastructure and necessary funding. Although this was the case for most countries in Europe and the north, Sweden was perhaps the most successful in implementing mass vaccination in an efficient manner and with high uptake (more than 60 per cent of the population). There were several discussions in the media, both regarding fears about the vaccine and its safety, and fears about not having enough. 'Why is the vaccine never coming, why isn't anything done, why so slow?' recalls one official about the reactions coming in to authorities.

What motivated people to get vaccinated or to vaccinate their children? Two surveys were made by the National Board of Health and Welfare during the summer before the campaign began, one in June and the other in July/August 2009. ${ }^{51}$ In the first, 72 per cent responded that they would get vaccinated and in the second 65 per cent; the slight decrease might have been influenced by concerns about the safety of the vaccine at this time. In both polls, only a small minority said that they felt really worried about the pandemic for their own health. About half of the respondents had sought information about the risks and how they could protect themselves and a majority thought that besides vaccination, hand washing was important. This indicates a relatively reflected and calm way of looking at the pandemic, and also a concern for the health of others as much as for oneself. That altruistic motives were important for people in their decision to be vaccinated was also shown in a later study. ${ }^{52}$

What were the arguments used by authorities for why people should get vaccinated? In the centrally produced information material spread during the weeks preceding the start of vaccination, three arguments for vaccination were put forward with equal emphasis: for your own sake to avoid disease; to protect those near you; and to stop the spread of infection in the community. There was some debate, especially around the third argument. Can you really appeal to people's altruism in a vaccination campaign? In the end, it was decided that this was appropriate, in part based on the results of the two above-mentioned vaccination surveys.

Although the underlying beliefs guiding the decisions were not always clearly articulated, there was a conviction among many experts and decision-makers that partial herd immunity could be accomplished in the short time before the influenza wave came, and that this could change the course of the epidemic in Sweden. Of course, there 
were the outspoken objectives of saving lives and protecting the healthcare system and other essential services from breaking down, but there was no decision to give any groups vaccination priority, with the exception of health-care workers and medical risk groups. In hindsight, this egalitarian policy could have had a positive effect on public trust in the state.

A further, often emphasised, factor was the unanimity that the different agencies, from the government down to the local municipalities, outwardly demonstrated. Even though the central authorities were playing a more dominant role than usual, local and regional governments seemed surprisingly loyal when implementing the recommendations. In general, there is an high degree of local autonomy in public health and health care in the Swedish system. Centralisation in managing the pandemic, with strong and united state guidance and local and regional implementation, was afterwards referred to as a 'Swedish model' and was regarded as one of the success factors of the vaccination campaign.

\section{A turning point}

We had a well worked out plan with the county councils and the like and that was why we were so successful. The whole of Europe was wondering, 'How did you manage?' So what would have turned out to be a success story became an Achilles heel when it was shown that the vaccine had such serious side-effects. ${ }^{53}$

I trusted them. One shot, and then my whole life changed. ${ }^{54}$

Both of the above quotations are important. The first concerns the trust that authorities initially had in their knowledge about how to handle the pandemic, while the second, which comes from one of the young people suffering from narcolepsy as a result of the vaccine, shows how this impacted public trust in the authorities. They illustrate important signs of a possible turning point in the Swedish public's historically deep trust in the welfare society's ability to provide health care and communicable disease prevention. Although it is too early to know if these experiences will endanger future mass vaccination efforts, it is certainly clear that this experience has caused doubt and disbelief. 
When the reports about narcolepsy cases began to arrive, the first reaction from authorities and medical experts was scepticism. It was hard to believe that the vaccine could cause this unknown disorder, since influenza vaccines had been used for eighty years without similar side effects. Almost five years after the mass vaccination efforts, in 2014, it has still not been determined whether this side effect is the result of a component of the vaccine, of the influenza virus itself, is due to genetic predisposition, or a combination of all these factors. It is evident that this unexpected side effect has had a deep impact on people's thoughts about vaccination in general and mass vaccination in particular. This is felt in the expressions of parents of narcoleptic children, such as: 'We placed our children on the sacrificial altar so that you all could remain healthy', or on the other side from parents of vaccinated children who were not affected, such as: 'We had the winning lottery ticket.' In a Swedish radio interview in May 2013, ${ }^{55}$ one young man was still hesitant about whether he had 'made it' and escaped being affected by narcolepsy, although more than three years had passed since his vaccination.

Many of the parents of narcoleptic children who were interviewed claimed that the argument for solidarity was very important in their decision to accept the vaccine. Their reasoning was that it was important to take the vaccine, that all siblings should have it, and this would be a way to protect other people or children who, for different reasons, could not take it. Among the officials interviewed, the importance of solidarity in order to reach herd immunity was also claimed, and for some this had ideological reasons.

I think the argument holds, I think it is one of the best arguments for vaccination in society. ... And it is not only to protect other people, you don't know where you will end up next time, maybe you are in the risk group yourself. So it is not only about solidarity. I think it is a rather fine argument, so to speak. ${ }^{56}$

Another official answered the question of whether Sweden exaggerated the solidarity argument.

If we signalled too strong or not? It is very hard to know ... But I think that all the work with preventing contagious diseases and the work with public health has in itself a very strong element of solidarity. You do things even if you don't know that you yourself will benefit from it. ${ }^{57}$ 
One of the interviewed officials did claim the opposite concerning solidarity, arguing that for these kinds of decisions it should never be demanded of people to have to think of others: every human being is entitled to think about him- or herself. ${ }^{58}$

References to solidarity are currently on the increase in public health discourse. During the 2009 pandemic, different countries emphasised the solidarity argument to different degrees. In Sweden, the argument that vaccination was both an act of solidarity as well as of individual self-interest was prominent in the authorities' communications. This seemed natural, since solidarity (in the sense of equality in a context of publicly financed health care) has traditionally been a central value in Swedish health-care policy. ${ }^{59}$ However, despite its significance, the term solidarity has been given different, sometimes contradictory meanings, both in academic and political contexts. Prainsack and Buyx ${ }^{60}$ are critical of the argument, claiming that state enforced public health measures such as vaccination cannot be argued for on the basis of solidarity, but require a different kind of justification, such as the duties of the state to protect vulnerable groups in a stewardship state model. Further arguments for the importance of solidarity have been proposed by Dawson and Verweij. ${ }^{61}$

\section{Consequences}

In preparation for a new law concerning vaccination, a Swedish governmental inquiry committee presented an analysis of the country's vaccine programmes. ${ }^{62}$ This work began in 2008, but was completed in 2010, and was most probably influenced by the debates triggered both by the newly introduced human papilloma virus (HPV) vaccine and mass flu vaccination. The inquiry proposes several changes to achieve an 'effective vaccination activity which enjoys a high level of trust among the population and attracts high uptake by the target groups. ${ }^{63}$ The problem of 'heavily distorted information' is addressed, in particular 'distorted, non-objective and scaremongering information that was a great problem in the initial stage of pandemic vaccination. ${ }^{64}$ This inquiry and other current governmental and bureaucratic processes show the importance of deep self-reflection and afterthought to prevent polarisation or divisions arising between different sides who blame each other for spreading disinformation. 
International management of the $\mathrm{A}(\mathrm{H} 1 \mathrm{~N} 1)$ 2009-10 swine flu pandemic has been subject to several evaluations concerning preparedness and response, all the way from assessing the WHO's global impact on decision-making to national, regional, and local evaluations. Forster stresses that globally and nationally, actors failed 'to correspond with more plural and variegated narratives constructed by multifarious publics, and so struggled to recruit support. ${ }^{65} \mathrm{He}$ also claims that influenza is still as slippery as in 1976, that expert knowledge is 'still speculative and incomplete, ${ }^{66}$ and that the persistence of a dominant and reductive framing of the problem constitutes the most important challenge when responding effectively to flu pandemics. The WHO, Forster argues, should be better at addressing these matters, but as it is bound to 'a reductive epistemology, and at the centre of an unreflexive, selfsustaining actor network, ${ }^{67}$ it cannot meet this challenge.

In the Swedish authorities' own evaluation, ${ }^{68}$ the main conclusions were that Sweden was successful in its management of the pandemic and that the mass vaccination campaign was launched and run relatively rapidly and efficiently. The authorities considered themselves basically successful in their communication with the public. The lack of a detailed plan for mass vaccination was noted as an area for improvement, as well as uncertainties about what constitutes the critical infrastructure requiring protection during a pandemic. The 2009 pandemic was officially considered a crisis in Sweden, above and beyond the everyday and familiar. In the national evaluation, the pandemic crisis was narrated as a social process, but this process was described in a very limited way and mostly from a top-down perspective, emphasising preparedness plans, governmental cooperation, and logistics.

The fact that different member states chose different paths for their vaccination strategies was embarrassing for the European Commission. The problem has long been acknowledged by EU officials, who have pushed for new legislation to strengthen the EU mandate to govern preparedness and the response to cross-border threats, be they infectious diseases or other hazards. One Swedish official remembered the procedures during the SARS epidemic.

It was shown that the EU countries handled it very differently. So if you coughed on the plane from Beijing to Frankfurt, they would take you off the plane in Frankfurt to X-ray your lungs. If you coughed on 
the plane from Beijing to London, you simply got off the plane and took the subway to London city. And these are matters that the EU hates, when countries handle things differently. And journalists love it of course. ${ }^{69}$

A strengthened EU mandate was achieved in decision 1082/2013/ EU on serious cross-border threats to health after long negotiations. ${ }^{70}$ With this, the Commission is now able to review the preparedness plans of member states and require that they are 'inter-operable'.

\section{Conclusions}

I would think, if we would have a similar situation [again], we wouldn't be able to have mass vaccination. I think we would offer it to everyone, but focus on the special risk groups ... I don't think the public would listen to a message which implies vaccinating children.

Why would I do that? Look what happened the last time you told us to. ${ }^{71}$

Public health policy concerning influenza treatment remains in a delicate balance between what should be done and what can be done. We claim that the management of influenza, both as a seasonal epidemic and even more so as a pandemic, still constitutes a serious and complex problem. Historically, there have been repeated failures in protecting the public and society from influenza pandemics, both because of a lack of consciousness of the problem, a lack of tools for effective protection, and both political under- and over-reaction at times.

Facing the $\mathrm{A}(\mathrm{H} 1 \mathrm{~N} 1)$ pandemic in 2009, the Swedish response was to bring their pandemic preparedness into efficient action, with mass vaccination being the most important intervention for protecting public health. These endeavours were preceded by consensual decisionmaking relying on historically successful vaccination campaigns. To act in this way could be labelled a typically Swedish way of managing a medical problem when the WHO called for global solidarity. Paradoxically, both this very efficiency and consensual decision-making may have harmed instead of strengthened trust in the authorities' ability to face future pandemics.

In their media analysis, Ghersetti and Odén discuss the lack of critical evaluation by the Swedish media during and after the pandemic. ${ }^{72}$ 
Even though there were critical voices, notably in one of the major newspapers, their conclusion is that the media failed in its responsibility to undertake a critical analysis of the rationale for mass vaccination and also for the advance purchase agreement. The few critical voices were drowned out in mass consensus among authorities, experts, and journalists.

Furthermore, there is a great need for critical reflexivity among all involved political and social institutions. This work is about looking back as well as ahead. What did we know? What could we know? What will we know? One official at the Institute for Communicable Disease Control concluded in February 2013:

I keep telling my co-workers: we did the best we could, we were not careless, we did not omit things. We have done our best and you cannot do more. And still things can happen, that's the way it is. Biology and human ... medicine is hard. We don't know everything, we have to admit that too. ${ }^{73}$

\section{Acknowledgements}

We are grateful for the information provided by officials at the Swedish National Board of Health and Welfare, the European Centre for Disease Prevention and Control, the Swedish Medical Products Agency, the Swedish Association of Local Authorities and Regions, and the Swedish Institute for Communicable Disease Control. We are also grateful to the Association for Narcolepsy (Narkolepsiföreningen) for providing information as well as the opportunity to interview parents of narcoleptic children.

This work is part of the research project 'Epidemics, Vaccination and the Power of Narratives', funded by the Marcus and Amalia Wallenberg Foundation in Sweden.

\section{Notes}

1 European Medicines Agency, '2009 (H1N1) Influenza Pandemic' (2014). http://www.ema.europa.eu/ema/index.jsp?curl=pages/special_topics/ general/general_content_000461.jsp\&mid=WC0b01ac05801 d7bfe (accessed 29 August). 
2 L. Wijnans, C. Lecomte and C. de Vries et al., 'The Incidence of Narcolepsy in Europe: Before, During, and After the Influenza A(H1N1) pdm09 Pandemic and Vaccination Campaigns', Vaccine, 31:8 (2013), pp. 1246-54.

3 G. Nylen, A. Linde, A. A. Kettis, O. Wik, S. Stenmark and M. Erntell, 'Health Personnel the Key to High Vaccination Coverage Against Influenza', Läkartidningen, 109:1-2 (2012), pp. 8-9.

4 See Andrea Stöckl and Anna Smajdor, 'The MMR Debate in the United Kingdom: Vaccine Scares, Statesmanship and the Media' (Chapter 9 in this book).

5 P. Sköld, The Two Faces of Smallpox - a Disease and its Prevention in Eighteenth- and Nineteenth Century Sweden (Umeå: Umeå University, 1996).

6 Ibid.

7 Ibid.

8 The National Board of Health, Allmän Hälso- och Sjukvård 1963 [Public Health in Sweden 1963], Annual Report of the National Board of Health (Stockholm 1965).

9 B. Zetterberg, O. Ringertz and A. Svedmyr et al., 'Smallpox Outbreak and Vaccination Problems in Stockholm, Sweden 1963. II. Case Histories', Acta Medica Scandinavica, Suppl. 464 (1966), pp. 45-56.

10 J. Sundin, C. Hogstedt, J. Lindberg and H. Moberg, Svenska folkets hälsa $i$ historiskt perspektiv [Swedish Public Health in a Historical Perspective] (Stockholm: Statens folkhälsoinstitut, 2005); P. Axelsson, Höstens spöke: de svenska polioepidemiernas historia [The Autumn Ghost: The History of Polio Epidemics in Sweden] (Stockholm: Carlsson, 2004).

11 A. Anell, A. H. Glenngård, 'Vacciner i Sverige - ett hälsoekonomiskt perspektiv [Vaccines in Sweden - a health economic perspective]: The Swedish Institute for Health Economics (2007).

12 A. R. Omran, 'The Epidemiologic Transition. A Theory of the Epidemiology of Population Change', Milbank Memorial Fund Quarterly, 49:4 (1971), pp. 509-38.

13 M. Singer, 'Pathogen-Pathogen Interaction: A Syndemic Model of complex Biosocial Processes in Disease', Virulence, 1:1 (2010), pp. 10-18.

14 R. E. Neustadt, H. V. Fineberg, 'The Swine Flu Affair: Decision-Making on a Slippery Disease (1978).

15 WHO, 'WHO/CDS/CSR/ ISR/2000.1' (2000).

16 D. Brockmann, D. Helbing, 'The Hidden Geometry of Complex, NetworkDriven Contagion Phenomena', Science, 342:6164 (2013), pp. 1337-42; C. I. Hsu, H. H. Shih, 'Transmission and Control of an Emerging Influenza 
Pandemic in a Small-World Airline Network', Accident Analysis \& Prevention, 42:1 (2010), pp. 93-100.

17 C. A. Russell, T. C. Jones, I. G. Barr et al., 'The Global Circulation of Seasonal Influenza A (H3N2) viruses', Science, 320:5874 (2008), pp. 340-6.

18 WHO, The World Health Report 2007. A Safer Future. Global Health Security in the 21st Century (Geneva, Switzerland: WHO, 2007).

19 G. Dehner, Global Flu and You. A History of Influenza (London: Reaktion Books, 2012).

20 WHO, 'WHO/CDS/CSR/ ISR/2000.1' (2000).

21 M. Åman. Spanska sjukan: den svenska epidemin 1918-1920 och dess internationella bakgrund [The Spanish Flu: The Swedish Epidemic 1918-1920 and its International Background] (Uppsala: Acta Universitatis Upsaliensis, 1990).

22 F. Elgh, 'Influensapandemiers påverkan på samhället' [The Impact of Influenza Pandemics on Society]', Socialstyrelsen (2006).

23 Åman, Spanska sjukan, p. 59.

24 S. A. Plotkin, W. A. Orenstein and P. A. Offit (eds), Vaccines (Philadelphia: Elsevier Saunders, 2013).

25 L. O. Kallings and H. Lundbäck, 'Statens Bakteriologiska Laboratorium (SBL) - en epok. [The National Bacteriological Laboratory (SBL) - an epoch]', Smittskydd, 9 (1999), pp. 91-95.

26 Interview with official at the Institute for Communicable Disease Control, February 2013.

27 B. Ehn, J. Frykman and Orvar Löfgren, Försvenskningen av Sverige. Det nationellas förvandlingar (Stockholm: Natur och Kultur, 1993).

28 H. Berggren and L. Trägårdh, Är svensken människa? Gemenskap och oberoende i det moderna Sverige (Stockholm: Norstedts, 2006).

29 D. E. Blakely, Mass Mediated Disease (Lanham, MD: Lexington Books, 2006).

30 L. Heller, B. Körlof, J. Mörner et al., 'Influensaepidemin i Sverige 1957-1958 Vaccinationsförsök' [The Influenza Pandemic in Sweden 1957-1958. Vaccination Trials]', Nordisk Medicin, 27:XI (1958), pp. 1706-10.

31 Elgh, 'Influensapandemiers påverkan på samhället'.

32 E. Holmer, Samhällets reaktioner på influensapandemierna 1957-58 och 1968-70 [Society's Reaction to the Influenza Pandemics 1957-58 and 196870], Umeå Universitet (2006).

33 Heller, Körlof, Mörner et al., 'Influensaepidemin i Sverige 1957-1958 Vaccinationsförsök', pp. 1706-10.

34 Elgh, 'Influensapandemiers påverkan på samhället'.

35 Blakely, Mass Mediated Disease, p. 145. 
36 Holmer, 'Samhällets reaktioner på influensapandemierna'.

37 SBL-kommittén, 'Report Ds S 1984:7' (1984).

38 See Stuart Blume, The Erosion of Public Sector Vaccine Production: The Case of the Netherlands (Chapter 6 in this book).

39 L. Rekke, 'Report Concerning Vaccine Production in Sweden', Social Ministry (2006).

40 Interview with official at the National Board of Health and Welfare, March 2013.

41 D. S. Fedson, C. Hannoun, J. Leese et al., 'Influenza Vaccination in 18 Developed Countries, 1980-1992', Vaccine, 13:7 (1995), pp. 623-7.

42 W. E. Beyer, I. A. de Bruijn, A. M. Palache et al., 'The Plea Against Annual Influenza Vaccination? “The Hoskins' Paradox" revisited', Vaccine, 16:20 (1998), pp. 1929-32.

43 Interview with official at the European Centre for Disease Prevention and Control, March 2013.

44 Interview with official at Swedish Association of Local Authorities and Regions, March 2013.

45 A. Lakoff, 'The Generic Biothreat, or How we Became Unprepared', Cultural Anthropology, 23:3 (2008), pp. 399-428.

46 Ibid.

47 Interview with official at the National Board of Health and Welfare, February 2013.

48 Interview with official at the National Board of Health and Welfare, March 2013.

49 Interview with official at the Institute for Communicable Disease Control, February 2013.

50 National Board of Health and Welfare, 'A(H1N1) 2009. An Evaluation of Sweden's Preparations for and Management of the Pandemic', Stockholm (2009)

51 Ibid.

52 B. Rönnerstrand, 'Social Capital and Immunisation Against the 2009 A(H1N1) Pandemic in Sweden', Scandinavian Journal of Public Health, 41:8 (2013), pp. 853-9.

53 Interview with official at the National Board of Health and Welfare, March 2013.

54 Daniela, 19 years, Svenska Dagbladet, 14 February 2012.

55 Sveriges Radio, 'Vetenskapsradion Forum' (2013).

56 Interview with official at the Institute for Communicable Disease Control, February 2013.

57 Ibid.

58 Ibid. 
59 D. Michailakis and W. Schirmer, Solidaritet som finansieringsform och som prioriteringsprincip [Solidarity as a Base for Funding and for Priority Setting] (Linköping University, 2011).

60 B. Prainsack and A. Buyx, Solidarity: Reflections on an Emerging Concept in Bioethics (London: Nuffield Council on Bioethics, 2011).

61 A. Dawson and M. Verweij, 'Solidarity: A Moral Concept in Need of Clarification', Public Health Ethics, 5 (2012), pp. 1-5.

62 Statens Offentliga Utredningar (SOU [Swedish Government Official Reports]), 'Ny ordning för nationella vaccinationsprogram' [New order for national vaccine programmes] (2010:39), pp. 45-8.

63 Ibid.

64 Ibid.

65 P. Forster, To Pandemic or Not. Reconfiguring Global Responses to Influenza (Brighton: STEPS Centre, 2012), pp. 49-50.

66 Ibid.

67 Ibid.

68 National Board of Health and Welfare, A(H1N1) 2009. An Evaluation of Sweden's preparations for and management of the pandemic (Stockholm, 2009).

69 Interview with official at the European Centre for Disease Prevention and Control, March 2013.

70 EU Parliament and Council, 'Decision No 1082/2013/EU', Official Journal of the European Union (2013).

71 Interview with official at the National Board of Health and Welfare, March 2013.

72 M. Ghersetti and T. A. Odén, Pandemin som kom av sig. Om svininfluensan $i$ medier och opinion [The pandemic that didn't come about] (Göteborg: Göteborgs universitet: Institutionen för journalistik, medier och kommunikation, 2010).

73 Interview with official at the Institute for Communicable Disease Control, February 2013. 